\title{
How to Measure Body Condition Score in Florida Beef Cattle ${ }^{1}$
}

\author{
Matt Hersom and Todd Thrift ${ }^{2}$
}

\section{Introduction}

Body condition score (BCS) is a visual assessment of the amount of fat in a cow's body. The amount of fat stored by the animal is a direct reflection of the amount of energy and protein that the cow has consumed. Excess energy intake is stored as fat, and adequate protein intake results in maximal muscle deposition. The deposition of fat and muscle leads to the appearance that creates a cow's BCS. Therefore, BCS is both a good indicator of the past nutritional status of the cow and a way to determine future nutritional needs.

\section{Reasons to Measure Body Condition Score}

Body condition score or change in body condition is a more reliable way to evaluate a cow's nutritional status than live weight or change in live weight. Live weight alone is not a good measure of overall nutritional status. Most cow herds have a range in frame size and muscling that makes BCS a better measure of body fat than live weight. Live weight is also affected greatly by gut fill, pregnancy status, forage quality, and forage availability. On many ranches, managers evaluate cow BCS regularly when weighing cows may be impractical. The BCS technique is easy to learn and can help with management decisions.

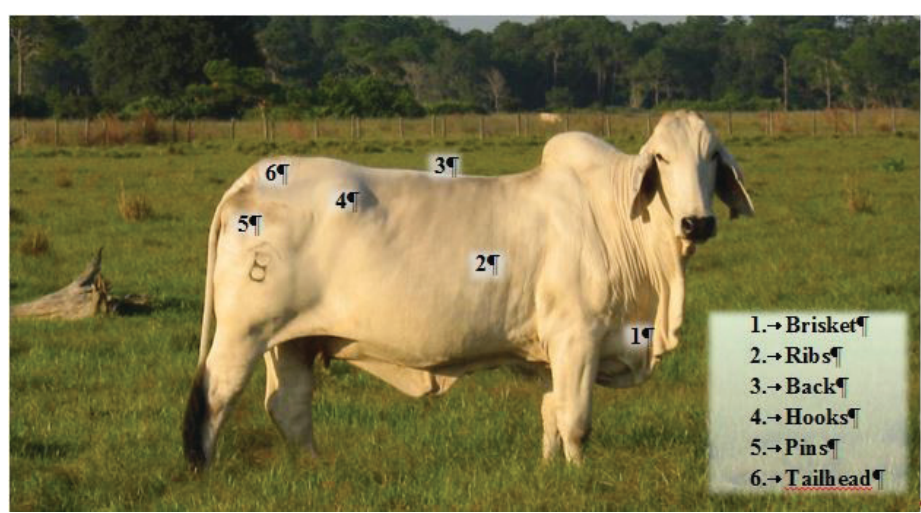

Figure 1. Assessment points for visual evaluation of cow body condition score.

Credits: Matt Hersom, UF/IFAS

\section{How to Measure Body Condition Score}

The body condition score for beef cows is assessed on a scale of 1 (thin) to 9 (obese). Many cattlemen and researchers use the BCS system as a subjective tool to evaluate cattle nutritional status. Keep in mind that the results of any visual scoring system will vary depending on the people conducting the scoring because different people will not always agree. However, experienced evaluators' ratings of BCS should not differ by more than one score. The first step in determining BCS is to know which areas of the body to evaluate (Figure 1). Fat deposits are visible in the brisket, and over the ribs, back/spine, hooks, pins, and tailhead.

1. This document is AN347, one of a series of the Department of Animal Sciences, UF/IFAS Extension. Original publication date August 2018. Visit the EDIS website at http://edis.ifas.ufl.edu.

2. Matt Hersom, associate professor; and Todd Thrift, associate professor, Department of Animal Sciences; UF/IFAS Extension, Gainesville, FL 32611.

The Institute of Food and Agricultural Sciences (IFAS) is an Equal Opportunity Institution authorized to provide research, educational information and other services

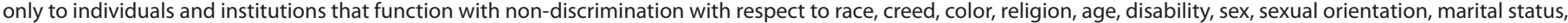

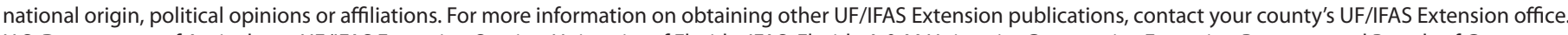
U.S. Department of Agriculture, UF/IFAS Extension Service, University of Florida, IFAS, Florida A \& M University Cooperative Extension Program, and Boards of County Commissioners Cooperating. Nick T. Place, dean for UF/IFAS Extension. 
If you have never assessed the BCS of beef cattle, the best way to start is to determine whether the cow is a BCS 5 or less than a BCS 5. If the last rib is not visible, the animal has a BCS greater than 5 . If the last rib $\left(13^{\text {th }} \mathrm{rib}\right)$ is the only rib visible, then the animal is a BCS 5. If multiple ribs are visible, then the animal is less than a BCS 5. An animal with a BCS of 5 should look neither thin nor fat. The ability to understand what a BCS 5 looks like is a key skill to develop. More specificity is needed when classifying cattle into three groups of BCS that correspond to the 9-point scale: thin (1 to 3 ), moderate (4 to 6 ), and fleshy (7 to 9). Most cattle should fall into the moderate category. Once you are comfortable with the three-group classification, you can assess BCS on the 9-point scale. Table 1 provides a description of each BCS.

Since BCS is a visual assessment, an orderly tracking of the eye over the body of the animal facilitates a standardized methodology. The initial survey is best conducted from the side of the animal; either side is fine. From the side, all six of the evaluation points are visible. One easy method is to initiate the assessment at the brisket and move back and up in a line that incorporates the ribs, spine, hooks, pins, and tailhead (Figure 2). This pattern connects all six locations and makes the evaluation of the transitions of fat deposition into those areas possible.

Figure 2 demonstrates a good example of a BCS 5 cow. Fat deposition has started in the brisket. The transition from the shoulder to the ribs is smooth, indicating full muscle status and fat deposition over the ribs. The last rib is just evident and the back is nearly flat with muscle and fat

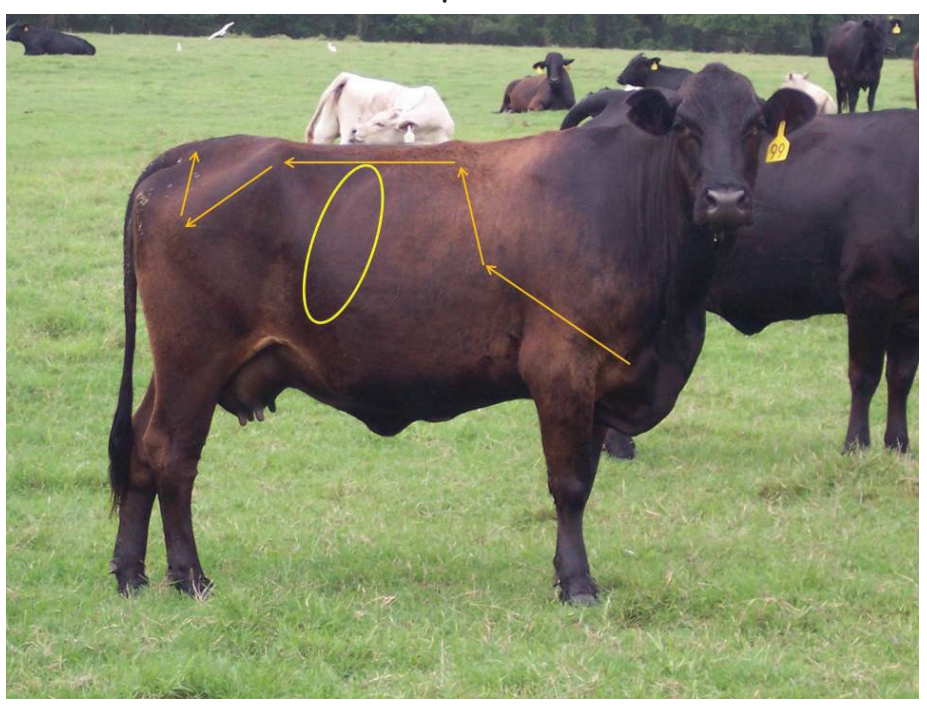

Figure 2. Path of assessment for all six body condition scoring points on the cow, starting at the brisket and proceeding to the ribs, back, hooks, pins, and tailhead. The circle indicates the last rib on this cow, revealing a body condition score of 5 .

Credits: Matt Hersom, UF/IFAS deposition. The hooks and pins are structurally evident, but smooth in appearance. Fat deposition around the tailhead creates a smooth transition from the hip structure to the tail bones.

Figure 3 shows an example of a BCS 3 cow. No fat deposition is evident in the brisket; a defined transition from the shoulder to the rib cage is visible, indicating decreased fat deposition over the shoulder into the ribs. Three to four ribs are evident. The spine creates a tent with the spinous processes forming the peak. The hooks and pins are evident, with sharpness over the hooks due to little fat deposition. Muscle is still evident in the hip, but muscle creases are also visible. Definition of structures around the tailhead is readily apparent because of little to no fat deposition.

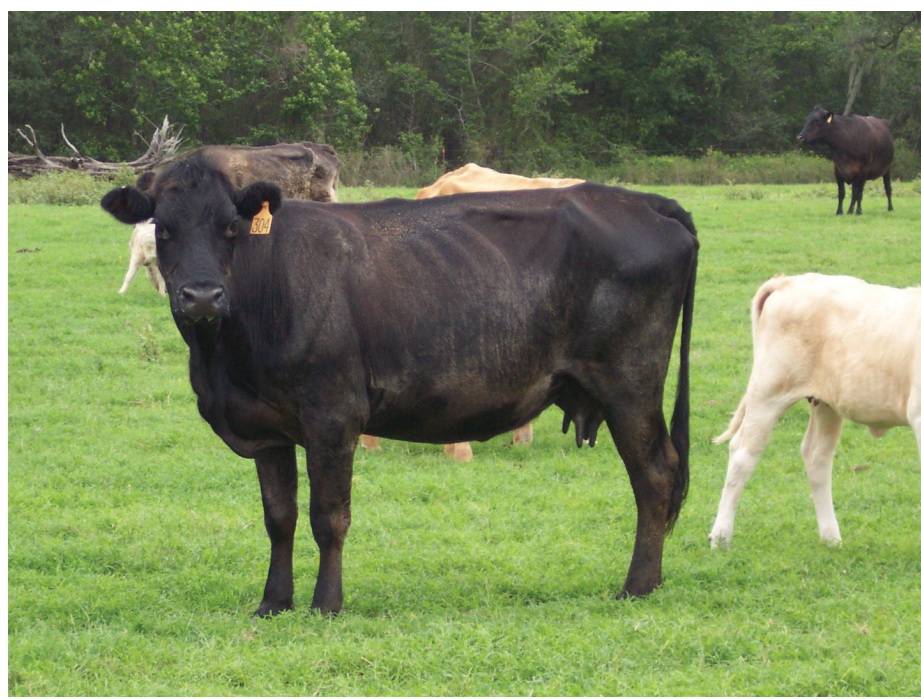

Figure 3. Example of a cow with a body condition score of 3. Little to no fat deposition in the brisket, four ribs visible, tenting appearance on the spine, hooks and pins clearly evident, and no fat deposition in the tailhead.

Credits: Matt Hersom, UF/IFAS

Figure 4 demonstrates a good example of a BCS 6 cow. There is fat deposition in the brisket; the transition from the shoulder to the ribs is smooth, indicating full muscle status and fat deposition over the ribs. No rib structures are evident, and the back is flat across the length with full muscle and fat deposition. The hooks are structurally evident, but they appear smooth because of fat deposition over the bones. The pins are not easily identified because they are fully covered with muscle and fat, resulting in a smooth appearance. Fat deposition around the tailhead obscures the structure with some mounding of fat in the area. 


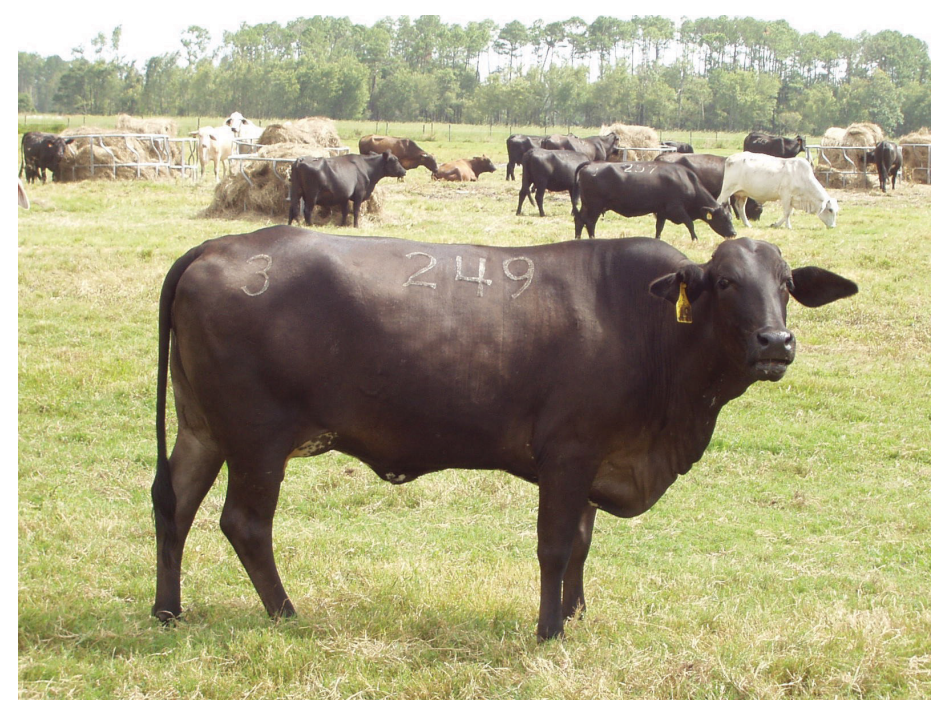

Figure 4. Example of a cow with a body condition score of 6 . Fat deposition in the brisket is plainly visible. No ribs can be seen. The back is flat across the length. Hooks are evident, but show fat cover. Pins are not visible because of full muscle and fat cover. The tailhead is covered with fat; some mounding is apparent.

Credits: Matt Hersom, UF/IFAS

Several things need to be considered when evaluating BCS of cattle. The fill or shrink from digestive contents or pregnancy can change the appearance of moderately fleshed cattle, especially over the rib or in front of the hooks. Long hair is another factor that can make it more difficult to evaluate BCS of a cow. If a cow has long hair, it can be helpful to physically palpate the cow over the back and ribs, and feel the flesh over the horizontal process of the spine in front of the hooks. The amount of flesh over the transverse process or sharpness of this bone can be used to help evaluate BCS. The descriptions in Table 1 can be used to facilitate palpation for BCS. The breed type can affect the areas where fat deposition occurs as well as cattle appearance. Some cattle with Bos indicus (Brahman) breeding show little fat deposition over the ribs, but deposit fat over the hooks and pins. Other cattle show uniform deposits of fat across the ribs and spine with no patchy deposits around the tailhead. The amount of skin in the dewlap of Bos indicus-influenced cattle can make the evaluation of fat deposition in the brisket a challenge. Variations in the skeletal and muscular dynamics of Bos indicus-influenced cattle compared with Bos taurus cattle present challenges to the untrained evaluator. Bos taurus cattle generally show thicker muscling with less angular and prominent skeletal structures than Bos indicus cattle.

A BCS range of 3 to 7 will include most beef cows in Florida. A cow of medium frame size will weigh approximately 1,200 lb at BCS 5 but only 1,030 lb at BCS 3 . In this system, a medium-frame beef cow would exhibit a change in weight of approximately $85 \mathrm{lb}$ for each condition score (National Academies of Sciences, Engineering, and Medicine 2016).

\section{Seasonal Changes in Condition Score}

The BCS of the beef herd will change during the year. The herd's mean BCS is usually highest in mid- to late summer, and it declines in the fall or winter. It is lowest in late winter or early spring. Forage quality and quantity as well as the cow's stage of production influence the variation in BCS. The rate of loss of BCS should be gradual and not extreme. During periods of high nutritional demand, it is preferable for the cows to lose BCS gradually over 120 days than to experience a very rapid loss in 45 days followed by consumption of high levels of supplemental feeds in an attempt to prevent further condition losses. We observed that cattle at either age extreme lose condition faster than other types of cattle, especially after calving. Young cattle have growth requirements that must be met along with lactation requirements immediately after calving that negatively affect BCS. Old cows may have teeth issues that impair forage consumption and negatively affect energy intake and BCS. It is important to monitor cattle closely and adjust forage and supplemental feeds to avoid high rates of BCS loss.

\section{When to Measure Body Condition Score}

Regular assessment of BCS in the cow herd is a good management practice. There are certain strategic times to measure BCS in cows that can affect the overall productivity of the herd. Below are some critical times to assess cow BCS in order to make management decisions and affect BCS changes.

- 90 days prior to calving: This is the last opportunity to have cows gain BCS before the demands of calving and lactation begin.

- Calving: Thin cows need to gain BCS to rebreed successfully; however, BCS gains during this period are costly and difficult to achieve because nutrient demand is highest at this time.

- Breeding: Thin cows need to gain BCS to rebreed successfully; however, BCS gains during this period are costly and difficult to achieve.

- 60 days prior to weaning: If cows are thin, the calves can be weaned successfully to decrease cow nutrient demand and dedicate nutrients to BCS recovery. 
- Weaning: This is the optimal time to recover cow BCS because of decreased nutrient requirements. Cows can be separated to provide additional nutrients to young and thin cows.

It is ideal to have cows at BCS 5 or higher at calving. If there is a considerable range in BCS in a herd, it may be desirable to separate thin cows. It is usually cost-prohibitive to supplement the entire herd if only half of the cows or fewer will respond to the higher level of nutrition. An alternative is to separate and manage thinner cows to improve their BCS prior to calving. Other possible alternatives may include grazing on a higher quality pasture, providing additional supplements, and/or treating for parasites. EDIS document AN319, Implications of Cow Body Condition Score on Productivity, details the effect of cow BCS on reproductive responses.

\section{Summary}

A BCS of 5 or higher at calving and through breeding is needed for good reproductive performance. Proper stocking rates, a good mineral supplementation program, and timely use of supplements offer the most potential to improve BCS. Separating cows by BCS at pregnancy testing or two to three months prior to calving and feeding groups to calve in BCS 5 or above will maintain high reproductive performance while holding supplemental feed costs to a minimum. The routine assessment of BCS will provide needed information to manage the cow herd for a high calf crop and profitability.

\section{References}

Hersom, M., T. Thrift, and J. Yelich. 2015. Implications of Cow Body Condition Score on Productivity. AN319. Gainesville: University of Florida Institute of Food and Agricultural Sciences. http://edis.ifas.ufl.edu/an319

National Academies of Sciences, Engineering, and Medicine. 2016. Nutrient Requirements of Beef Cattle: Eighth Revised Edition. Washington, D.C.: The National Academies Press. https://doi.org/10.17226/19014 
Table 1. Description of 9-point body condition scores (BCS).

\begin{tabular}{|c|c|c|}
\hline $\mathrm{BCS}$ & & Description \\
\hline 1 & Emaciated & $\begin{array}{l}\text { Bone structure of shoulder, ribs, back, hooks, and pins sharp to touch and easily visible. Little evidence of } \\
\text { fat deposits anywhere on the body. Muscle structure is minimal. }\end{array}$ \\
\hline 2 & Very Thin & $\begin{array}{l}\text { Little evidence of fat deposits, but some muscling in hindquarters. Skeletal structure is still visible. The } \\
\text { spinous processes feel sharp to the touch and are easily seen with space between them. Most ribs are still } \\
\text { visible. }\end{array}$ \\
\hline 3 & Thin & $\begin{array}{l}\text { Beginning of fat cover over the loin, back, and fore ribs. Backbone still highly visible. Processes of the } \\
\text { spine can be identified individually by touch and may still be visible. Spaces between the processes are } \\
\text { less pronounced. Brisket has no fat deposition. Pelvic structure (i.e., hooks and pins) is still pronounced. }\end{array}$ \\
\hline 4 & Borderline & $\begin{array}{l}\text { Fore ribs not noticeable. } 12^{\text {th }} \text { and } 13^{\text {th }} \text { ribs still noticeable to the eye, particularly in cattle with a big } \\
\text { spring of rib, with ribs wide apart. The transverse spinous processes can be identified only by palpation } \\
\text { (with slight pressure) and feel rounded rather than sharp. Full muscling in the hindquarters, but lean in } \\
\text { appearance. }\end{array}$ \\
\hline 5 & Moderate & $\begin{array}{l}12^{\text {th }} \text { and } 13^{\text {th }} \text { ribs not easily visible unless the animal has shrunk. The transverse spinous processes are not } \\
\text { noticeable to the eye and can only be felt with firm pressure; these feel rounded. Spaces between the } \\
\text { processes are not visible and can only be detected with firm pressure. Areas on each side of the tailhead } \\
\text { are fairly well-filled but not mounded. Fat deposition in the brisket is observed. }\end{array}$ \\
\hline 6 & Good & $\begin{array}{l}\text { Ribs not noticeable to the eye because they are fully covered with fat. Hindquarters plump and full. } \\
\text { Noticeable sponginess to covering of fore ribs and on each side of the tailhead. Firm pressure now } \\
\text { required to feel transverse processes. Brisket fat is noticeable. }\end{array}$ \\
\hline 7 & Very Good & $\begin{array}{l}\text { Ends of the spinous processes can only be felt with very firm pressure. Spaces between processes can } \\
\text { barely be distinguished at all. Abundant fat cover on either side of tailhead with some patchiness evident. } \\
\text { Brisket is becoming full with fat. }\end{array}$ \\
\hline 8 & Fat & $\begin{array}{l}\text { Animal taking on a smooth, blocky appearance; bone structure disappearing from sight. Thick and } \\
\text { spongy fat cover with likely patchiness. }\end{array}$ \\
\hline 9 & Very Fat & $\begin{array}{l}\text { Bone structure not seen or easily felt. Tailhead buried in fat. Animal's mobility may be impaired by excess } \\
\text { fat. }\end{array}$ \\
\hline
\end{tabular}

